\title{
On the Extension of the XAI-based Medical Diagnostics DSS for the Treatment and Care of Patients
}

\author{
Vytautas Petrauskas*, Raimundas Jasinevicius*, Life Member, IEEE, Egidijus Kazanavicius*, \\ Zygimantas Meskauskas* \\ * Centre of Real Time Computer Systems, Kaunas University of Technology
}

DOI: 10.29322/IJSRP.11.11.2021.p11931

http://dx.doi.org/10.29322/IJSRP.11.11.2021.p11931

\begin{abstract}
This paper suggests to extend the earlier proposed XAI-based medical diagnostic decision support system with a new functionality for the treatment and care elderly patients. The proposed extension is considered as a partial case of the universalized fuzzy SWOT maps network. The main idea was realized in a module called as LEVERAGE and was successfully simulated. The reliable results presented in this paper have confirmed a vitality of the idea. This paper also advocates the breakthrough in believes that the theories about diseases are good ones only if they offer treatment as well. The paper concludes with a list of necessary future research.
\end{abstract}

Index Terms- Explainable artificial intelligence (XAI), Computing with words (CWW), Medical decision support systems (MDSS), Diagnostic, Geriatric syndromes, Treatment, Fuzzy SWOT maps (FSM), Fuzzy logic based reasoning, Verbalization, Degree of certainty, Fuzzy expert maps (FEM), Membership function, Fuzzy logic terms..

\section{Introduction}

$I^{\mathrm{n}}$ today's age of a wide variety of computer systems and artificial intelligence (AI) technologies, no one doubts the importance, capabilities, and significance of decision support systems (DSS).Just ask in the GOOGLE system, for example, "decision support systems today" and the system provides data on more than 1.250 million links in 0.79 sec., and $25 \%$ of them cover decision support systems healthcare (362 million links) mostly for medical diagnosis.

We would like to emphasize that a few years ago the Clinic of Geriatrics (CoG) of the Faculty of Nursing of Medical Academy in Lithuanian University of Health Sciences (LSMU) and the Center of Real Time Computer Systems (CRTCS) of the Faculty of Informatics in Kaunas university of Technology (KTU) have started research in a very sensitive area of application of decision support systems such as diagnostics of geriatric patients. The joint team of researchers of CoG and CRTCS was encouraged by the [1] and has started the new approach to the medical diagnostics DSS based on analysis of strengths, weaknesses, opportunities and threats of the system or problem under investigation(SWOT analysis) combined with elements of explainable artificial intelligence (XAI), computing with words (CWW) and general complex systems theory. This approach step-by step was published in ([2] - [5]) and its vitality at last was confirmed and presented in [6]. Concluding remarks of the [6] say that during the initial testing, the model was used by both: the experienced professionals and trainees, as well as several students. The general opinion is that 1) the diagnoses presented by the model correlate well with the diagnoses of specialists, and 2 ) that it is convenient to work with such a tool. This suggests that the model deserves further practical research and development as a prototype later to be incorporated into geriatric practice to assess the health status of patients according to the symptoms and factors used in medical practice, to identify health risks, and to present the most likely syndromes or diseases.

As a matter of fact in the case of health care systems, the tasks of decision support systems are much broader than just diagnostics. DSS must advise, suggest and help to organize the treatment and care of patients. It means that we need the extension of the model described in [6].

So medical DSS should advise, suggest and assist in the organization of patient treatment and care. This means that we need to expand the model developed and presented in [6] and supplement it with opportunities to provide treatment advice on recommended medications, types of patient care, diets, and other effective factors based on the results of the diagnosis. This publication is intended to describe the necessary further research related to the extensions of the model presented in [6]. Further one of those extensions is called as LEVERAGE module.

This paper is organized as follows: the preliminaries are presented in Section 2,and the Section 3is devoted for modeling results of an extension of the XAI-based MDSS for the patients' treatment. Finally -the conclusions with the list of future research and acknowledgements are drawn in Section 4.

\section{Preliminaries}

It is worth to emphasize that the Centre of Real Time Computer Systems of Kaunas University of Technology (CRTCS) has proposed a new universalized concept of a system using a dynamic SWOT analysis network called fuzzy SWOT map (FSM) for fuzzy control of risk in complex environments([3$5]$ ), and the fuzzy cognitive expert maps (FEM) type network ([7], [8]) for the aggregation of proper leverages, recommendations, or even immediate actions to be taken that would enable improvement of the situation. That part of system is called LEVERAGE for simplicity and is also built on the fuzzy cognitive expert maps (FEM) type network consisting of elements operating on the expert knowledge presented in the form of the lists of IF... THEN type fuzzy logic rules (LoR) [3]. The philosophy of such a network fully covers the functioning of many real systems, including medical decision support systems 
(MDSS) such as the DSS, developed, implemented and tested by CRTCS and CoG [9].

The systemic structure of generalized MDSS is based on the description of functional organization of its main parts, delivered in [3], [4] and [6] as well as in the [9], is presented in Figure 1.

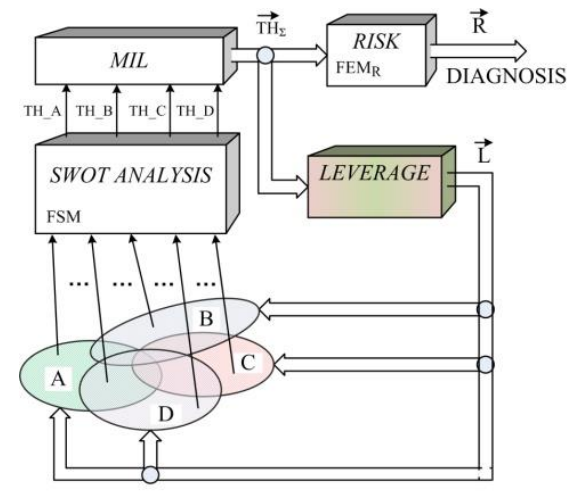

Fig. 1. The systemic structure of the generalized MDSS.

Here the SWOT analysis block (SWOT ANALYSIS) creates corresponding fuzzy SWOT maps (FSM) discussed earlier and evaluates threats (TH) emerging in all overlapping and interacting environments A, B, C, and D. Here as well as in the case earlier presented in [6] A, B, C, and D stand for four mutually influencing syndromes and their symptoms such as MALNUTRITION (A), OROPHARYNGEAL DYSPHAGIA (B), DEHYDRATION (C) and eating disorder in DEMENTIA (D)

The MIL block uses the corresponding matrix $W_{\text {MIL }}$, representing influential mutual linkages of all possible THs (TH_A, TH_B, TH_C and TH_D) and presents all summarized vectors of threats (TH) $\overrightarrow{T H}_{\Sigma}$. The main operation describing these influences and interactions between SWOT engines of any FSM is the matrix $\mathrm{W}_{\mathrm{MIL}}$ representing influential linkages (MIL) on the FSM under consideration.

This matrix $W_{\text {MIL }}$ performs the following operation on the INPUT vector $\vec{X}$ in order to receive the OUTPUT vector $\vec{Y}$ :

$\vec{Y}=W_{\mathrm{MIL}} \vec{X}$

Here $\vec{X}=\left(T H \_A, T H \_B, T H \_C, T H \_D\right)$,

and $\vec{Y}=\left(T H_{W \Sigma A}, T H_{W \Sigma B}, T H_{W \Sigma C}, T H_{W \Sigma D}\right)$,

The coefficients $W \mathrm{x}_{\mathrm{i}} \rightarrow \mathrm{y}_{\mathrm{j}}$ of the matrix $W_{\mathrm{MIL}}$ are correspondingly such that $\mathrm{i}=\mathrm{A}, \mathrm{B}, \mathrm{C}, \mathrm{D}$, and $\mathrm{j}=\mathrm{A}, \mathrm{B}, \mathrm{C}, \mathrm{D}$, and mean positive or negative influence of the element $x i$ to the element $y_{i}$.

The RISK block uses fuzzy expert maps $\left(\mathrm{FEM}_{\mathrm{R}}\right)$ mechanism and evaluates all possible risks $\vec{R}$ necessary to be able to announce the diagnosis. And the main block LEVERAGES suggests the usage of certain leverages $\vec{L}$ (recommendations, actions, medicine, type of patient's care and so on) as a result of MDSS reasoning in this block of fuzzy expert maps $\mathrm{FEM}_{\mathrm{L}}$ mechanism.

Such a systemic structure of generalized MDSS is built and its activity is demonstrated in the following Section 3 for a simplified real case because it is obviously clear that Ralf Waldo Emerson ([10]) was right saying that the theories about diseases are good ones only if they offer treatment as well. So MDSS proposed in [6] must not only to diagnose but be able to advise, suggest and help to organize the treatment and care of elderly patients.

\section{Modeling Of The Main Idea Of An Extension Of The XAI-based MDSS For The Patients' Treatment And Care}

To demonstrate the idea of an extension model, an artificial case/example was chosen, the roots of which extend from the situations described in [6]. To this end, the arsenal of overcoming and treating the threats of possible/existing syndromes in question, such as medications, diet, treatment and nursing versions, etc., was firstly examined in summary.

It was found that most of the recommendations, advices and actions belong to one of two groups: or 1) answering the question HOW MUCH? (i.e., a numerically measurable subject), or 2) answering the question WHICH? (i.e., certain object choosing from an available set).

Secondly, three examples of treatment and nursing recommendations were selected: 1) (MEDICINE) to offer the amount of active substance of a particular drug to the patient to inject daily (answer to the question HOW MUCH?); 2) (DIETA) to select the most suitable diet for the patient from the list of possible diets arranged according to certain characteristics; and 3) (CARE) to recommend to the patient a certain optimal treatment and care option. Recommendations for DIET and CARE answer the question WHICH?, and are selected from the corresponding lists of possible finite sets.

Thirdly, in the example, the amount of the medicine in question administered to the patient was considered to be determined by the risk levels for dementia (D) and oropharyngeal dysphagia (B) $\mathrm{TH}_{\Sigma \mathrm{D}}^{\star}$ and $\mathrm{TH}_{\Sigma \mathrm{B}}^{\star}$ correspondingly. Similarly the diet to be selected depends on the levels of threat of the dehydration (C) and malnutrition (A) $\mathrm{TH}_{\Sigma \mathrm{C}}^{\star}$ and $\mathrm{TH}_{\Sigma \mathrm{A}}^{\star}$; also the type of care is assumed as predetermined by the levels of threats of dementia (D) and dehydration $(\mathrm{C})$ : $\mathrm{TH}_{\Sigma \mathrm{D}}^{\star}$, and $\mathrm{TH}_{\Sigma \mathrm{C}}^{\star}$.

So the general implementation of the model of the extension is presented in Figure 2.

The whole FEM network for this example consists of the three fuzzy expert map elements (FEM MEDICINE, FEM DIET and FEM CARE) each with its own list of fuzzy rules ( $\operatorname{LoR}_{\mathrm{MED}}$, LoR $_{\text {DIET }}$ and LoR CARE$_{\text {) }}$ containing a concentrate experts' knowledge summarized during medical practice. The square brackets for the output of each FEM emphasize that they represent a numerical value usually received as a result of defuzzification performed by the fuzzy operation of determination of $\mathrm{CoG}$ (center of gravity). The $\left[\mathrm{L}_{\mathrm{MED}}\right]$ is ready to be used as an amount of recommended active substance of a particular medicine for the patient. But $\left[\mathrm{L}_{\mathrm{D}}\right]$ and $\left[\mathrm{L}_{\mathrm{C}}\right]$ must be fuzzified and expressed in verbal form as $\left\{\mathrm{L}_{\mathrm{D}}\right\}$ and $\left\{\mathrm{L}_{\mathrm{C}}\right\}$ and supplied by additional information meaning the level of certainty $\mu$ of each assigned word. Those curly brackets just signify that variables are words. The blocks of such a fuzzification are also presented in the Figure 2. 


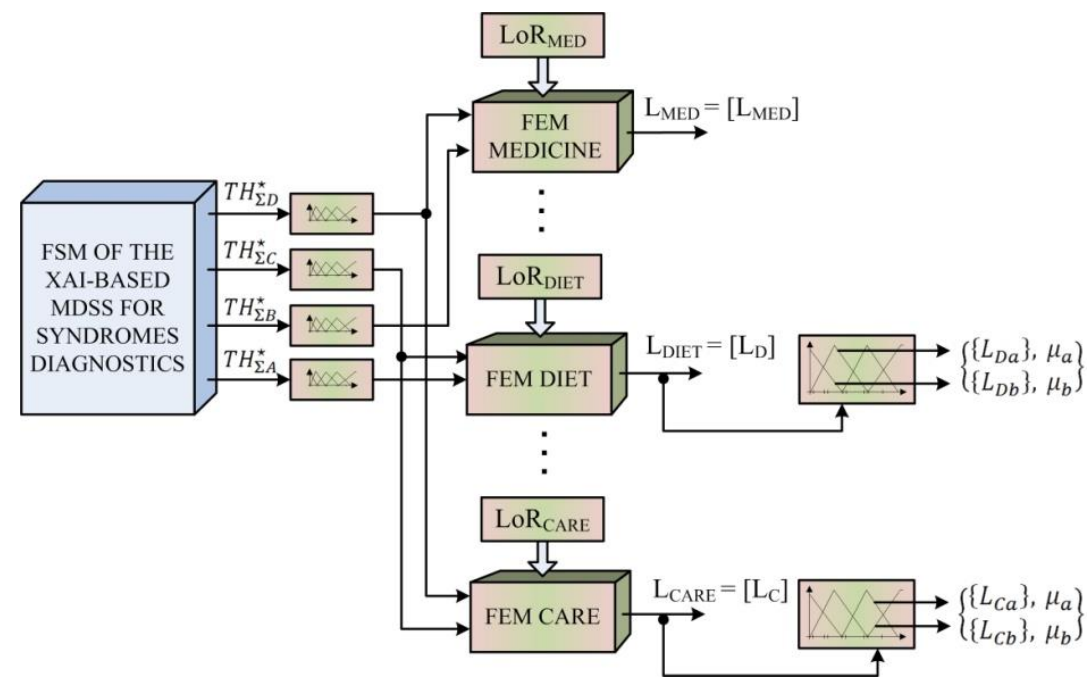

Fig.2. The block diagram of the model LEVERAGES of extension for the XAI-based MDSS.

Functionality of the model LEVERAGES (an extension for the XAI-based MDSS) was simulated using FuzzyTECH8.62f software package described in [11]. The initial screen shot of this simulated model is delivered in Fig. 3, and the results of simulation are step by step presented later together with the corresponding explanations.

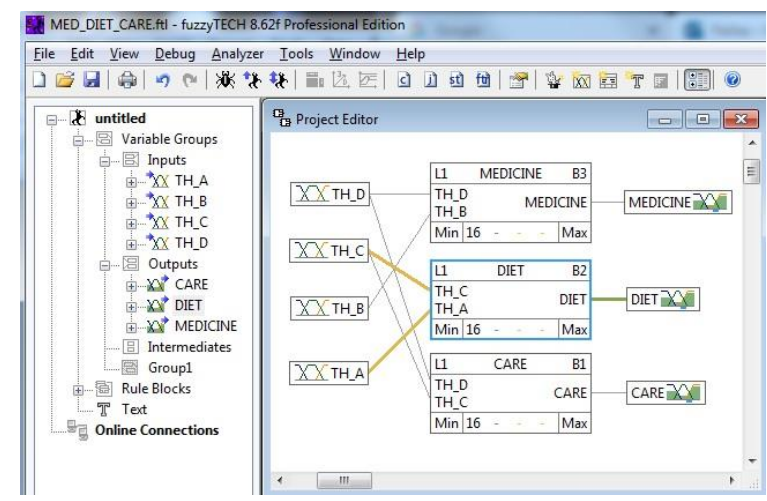

Fig. 3. The screen shot of the LEVERAGE model description

First of all must be stressed that during the whole process of simulation the same fuzzy terms for each FEM module were used for fuzzification of input variables $\mathrm{TH}_{\Sigma \mathrm{e}}^{\star}$ for $\mathrm{e}=\mathrm{A}, \mathrm{B}, \mathrm{C}$ and $\mathrm{D}$. The vocabulary of words and corresponding fuzzy terms are shown in Fig. 4 ([6])

$$
\begin{aligned}
& \{N\}-\text { None } \\
& \{S\}-\text { Small } \\
& \{M\}-\text { Medium } \\
& \{L\}-\text { Large }
\end{aligned}
$$

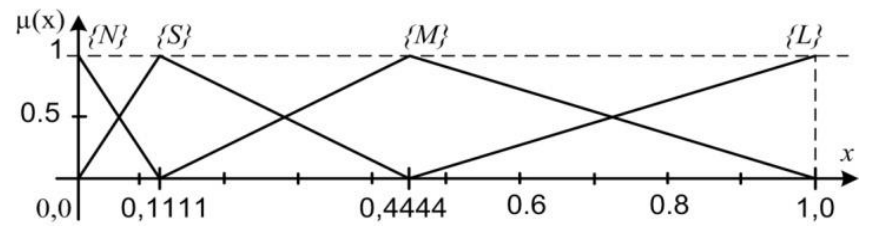

Fig.4. Vocabulary of words and fuzzy terms for input variables

For the CoG determinations at the FEM outputs as well as for the secondary fuzzification (when it is necessary like in case of FEMs for DIET and CARE) a slightly different or more precise (richer) vocabulary and set of fuzzy terms was used (see Fig. 5).

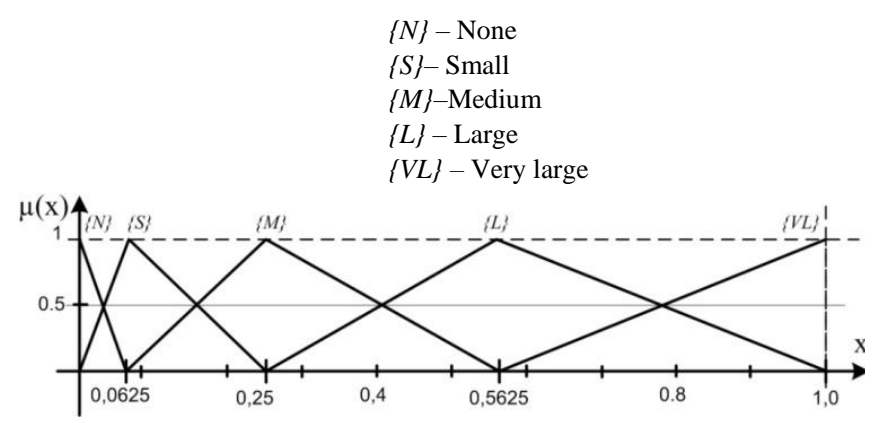

Fig. 5. Vocabulary of words and fuzzy terms for LEVERAGE outputs

So, results of determination of [ $\left.\mathrm{L}_{\mathrm{MED}}\right]$-the amount of active substance of a particular medicine to the patient to inject daily were based on the list of expert rules (LoR $\left.\mathrm{R}_{\mathrm{MED}}\right)$ presented in the Fig. 6. The results are obtained by simulating the case when maximal possible amount of the active substance in this medicine

\begin{tabular}{|c|c|c|c|}
\hline Name & 粸 If & And & Then \\
\hline \multicolumn{4}{|l|}{ MEDICINE } \\
\hline & XX $X$ TH_D: 0,25 & $X \times$ TH_B: 0,25 & $\gtrsim \overrightarrow{~ M E D I C I N E: ~} 135,76$ \\
\hline & M TH_D.N & $\Lambda$ TH_B.N & $\Lambda \quad$ MEDICINE. $N$ \\
\hline & LA TH_D.N & $\Lambda$-TH_B.S & $\perp \Lambda$ MEDICINE.S \\
\hline & IN TH_D.N & 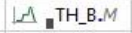 & L MEDICINES $S$ \\
\hline & H TH_D.N & $\lfloor$ TH_B.L & $\Lambda$ I MEDICINE.M \\
\hline & $M$ TH_D.S & $\Lambda \quad$ TH_B.N & $\Lambda \quad$ MEDICINE. $N$ \\
\hline & INTH_D.S & $\Lambda$-TH_B.S & $1 \Lambda$ MEDICINE.M \\
\hline & H IH_D.S & INH_B.M & $\Lambda \_$MEDICINE. $L$ \\
\hline & 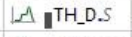 & $\Lambda$ TH_B.L & $\Lambda$, MEDICINE. $V L$ \\
\hline & $\Lambda$.TH_D.M & $\Lambda$ TH_B.N & $\Lambda$ I MEDICINE.M \\
\hline & $\Lambda \|^{T H} \_D . M$ & $\Lambda$ "TH_B.S & $\Lambda . M$ MEDICINE $L$ \\
\hline & $\Lambda$,TH_D.M & IN & $\perp$, MEDICINE. $V L$ \\
\hline & $\Lambda \|_{\|}^{T H}-D \cdot M$ & $\Lambda$ TH_B.L & $\Lambda$. MEDICINE. $V L$ \\
\hline & $\lfloor\Lambda$ TH_D.L & $\Lambda \quad$ TH_B.N & $\Lambda$. MEDICINE.L \\
\hline & $\Lambda$ TH_D.L & $\Lambda$ 【TH_B.S & $\Lambda$. MEDICINE. $V L$ \\
\hline & $\Lambda$ TH_D.L & $M$-TH_B.M & $L$, MEDICINE $L$ \\
\hline & $\Lambda$ TH_D.L & $\Lambda$ TH_B.L & $\Lambda$. MEDICINE. $L$ \\
\hline
\end{tabular}
is $250 \mathrm{mg}$ (what corresponds to 1 on the horizontal axis of the set of fuzzy terms). The dependence of function [ $\left.\mathrm{L}_{\mathrm{MED}}\right]$ on $\mathrm{TH}_{\Sigma \mathrm{D}}^{\star}\left(\mathrm{TH} \_\mathrm{D}\right)$ and $\mathrm{TH} H_{\Sigma \mathrm{B}}^{\star}\left(\mathrm{TH} \_\mathrm{B}\right)$ is presented in Fig. 7.

Fig. 6. List of fuzzy rules LoR $_{M E D}$ 


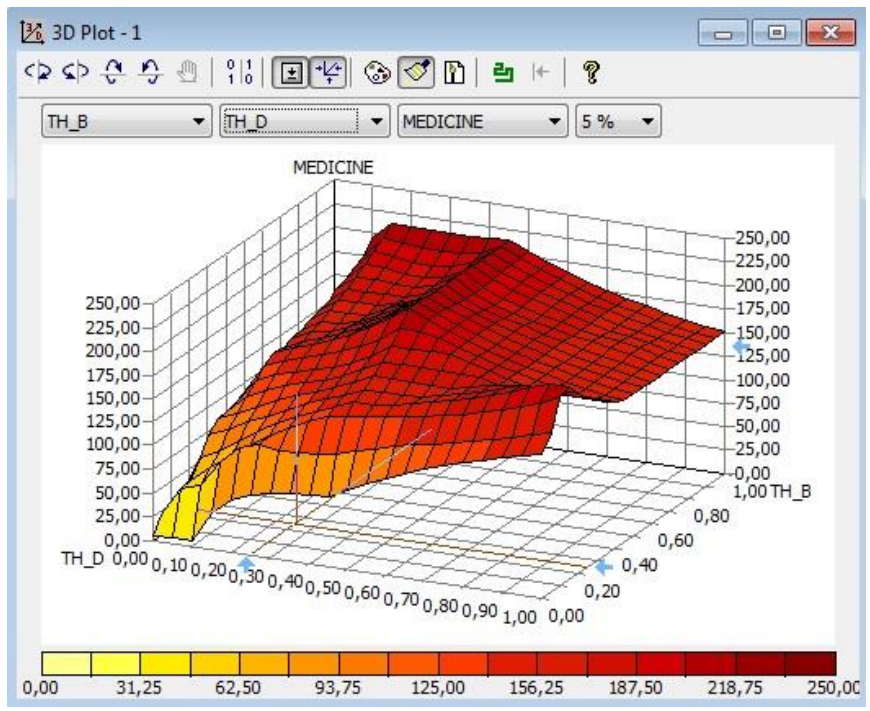

Fig. 7. The $\left[\mathrm{L}_{\mathrm{MED}}\right]$ as a function of $\mathrm{TH}_{\Sigma \mathrm{D}}^{\star}\left(\mathrm{TH} \_\mathrm{D}\right)$ and $\mathrm{TH}_{\Sigma \mathrm{B}}^{\star}\left(\mathrm{TH} \_\mathrm{B}\right)$

The concrete recommendation of the prescription of $\left[\mathrm{L}_{\mathrm{MED}}\right]=$ $135.8 \mathrm{mg}$ corresponds to the case when $\mathrm{TH}_{\Sigma \mathrm{D}}^{\star}\left(\mathrm{TH} \_\mathrm{D}\right)=0.25$ and $\mathrm{TH}_{\Sigma \mathrm{B}}^{\star}\left(\mathrm{TH} \_\mathrm{B}\right)=0.25$ as it is shown in Figure 8.

\begin{tabular}{|c|c|c|c|}
\hline Name & 䝔 If & And & Then \\
\hline \multicolumn{4}{|l|}{ DIET } \\
\hline & ${ }^{*} \times \mathrm{TH}$ TC: 0,25 & $X \times$ TH_A: 0,25 & 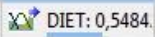 \\
\hline & $\Lambda$ TH_C.N & $\Lambda$ TH_A.N & $\perp \quad$ DIET. $N$ \\
\hline & $\Lambda$ TH_C.N & $\Lambda$ ॥TH_A.S & $\Lambda \quad$ DIET. \\
\hline & $\Lambda$ TH_C.N & $\Lambda$ ॥TH_A.M & $\Lambda$. DIET. $/ I$ \\
\hline & $\Lambda$ TH_C.N & $\perp \Lambda$ TH_A.L & $\Lambda$ ॥ DIET. $/ I$ \\
\hline & $\Lambda \|^{\mathrm{T}} \mathrm{H}_{-} \mathrm{C} . \mathrm{S}$ & $\Lambda$ TH_A.N & $\perp \quad$ DIET. $/$ \\
\hline & $\Lambda \|^{T H}$-C.S & $\Lambda$ \TH_A.S & $\Lambda \|$ DIET. $\| l \mid$ \\
\hline & $\Lambda \|^{T H} H_{-} C . S$ & $\Lambda$ ॥TH_A.M & $\Lambda$. DIET..$/ I$ \\
\hline & $\Lambda \|^{T H} \_C . S$ & $\Lambda$ TH_A.L & $\Lambda$. DIET.III \\
\hline & $\Lambda$ ॥TH_C.M & $\Lambda$ TH_A.N & $\Lambda$. DIET.IIII \\
\hline & $\Lambda$ 【TH_C.M & $\Lambda$ \} \text { TH_A.S } $&{\Lambda=\text { DIET. } I V} \\
{\hline} &{\Lambda \text {.TH_C.M }} &{\Lambda \text {.TH_A.M }} &{\Lambda \text { DIET. } I V} \\
{\hline} &{\Lambda \text {.TH_C.M }} &{\Lambda \text { TH_A.L }} &{\Lambda \text {. DIET.IIII }} \\
{\hline} &{\perp \Lambda \quad T H \_C . L} &{\perp \text { TH_A.N }} &{\Lambda \text {. DIET.IIII }} \\
{\hline} &{\Lambda \quad T H \_C . L} &{\Lambda \text { \.TH_A.S }} &{\Lambda \text {. DIET.JIII }} \\
{\hline} &{\Lambda \text { TH_C.L }} &{\Lambda \text { ॥TH_A.M }} &{\Lambda \text {. DIET. } . / I} \\
{\hline} &{\Lambda \quad T H \_C . L} &{\Lambda \text { TH_A.L }} &{\Lambda \text { ॥ DIET. } / /} \\
$\hline
\end{tabular}

a)

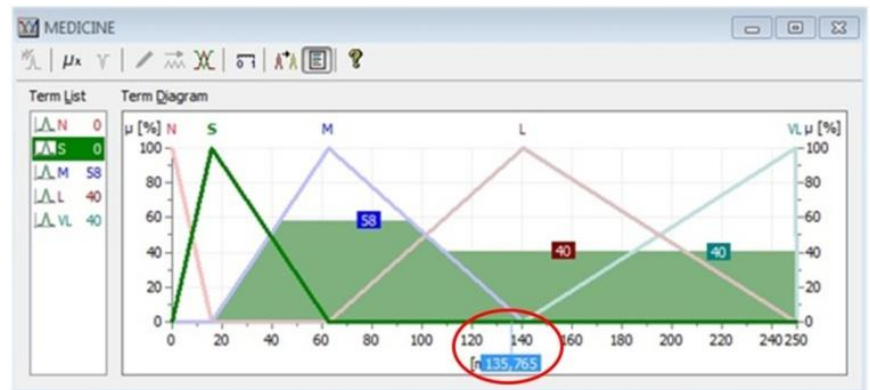

Fig. 8. The recommended prescription of [LMED] $=135.8 \mathrm{mg}$

FEM DIET and FEM CARE (Fig. 2) work similarly: a) the first one evaluates the [LDIET] as a function of $\mathrm{TH}_{\Sigma \mathrm{C}}^{\star}$ (TH_C) and $\mathrm{TH}_{\Sigma \mathrm{A}}^{\star}$ (TH_A) according to the list of fuzzy rules LoR $\mathrm{LIET}_{\mathrm{D}}$

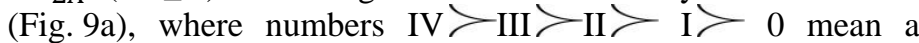
sequence of diets arranged, for example, according to the amount and quality of crushed vegetables and fruits, and the second one b) evaluates the [LCARE] as a function of $\mathrm{TH}_{\Sigma \mathrm{D}}^{\star}\left(\mathrm{H}_{-} \mathrm{D}\right)$ and $\mathrm{TH}_{\Sigma \mathrm{C}}^{\star}$

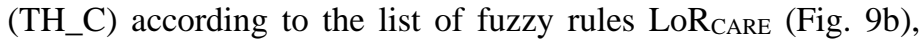
where N- means patient independence, HOME - home treatment, AMBULAT means outpatient treatment, HOSPITAL means hospital treatment, CARE means nursing home.

The dependence of [LDIET] as a function of $\mathrm{TH}_{\Sigma \mathrm{C}}^{\star}$ (TH_C) and $\mathrm{TH}_{\Sigma \mathrm{A}}^{\star}$ (TH_A) is shown in Fig. 10a as well as the dependence of [LCARE] as a function of $\mathrm{TH}_{\Sigma \mathrm{D}}^{\star}$ and $\mathrm{TH}_{\Sigma \mathrm{C}}^{\star}$ is shown correspondingly in Fig. 10b.

\begin{tabular}{|c|c|c|c|}
\hline Name & 葚 If & And & Then \\
\hline \multicolumn{4}{|c|}{ CARE } \\
\hline & $\Rightarrow \times$ TH_D: 0,25 & $5 \Rightarrow \times X$ TH_C: 0,25 & W CARE: 0,4518 \\
\hline & M TH_D.N & $\Lambda$ TH_C.N & $\Lambda$ CARE. $N$ \\
\hline & M TH_D.N & $\Lambda_{\mathbf{I}} \mathrm{TH} \mathrm{H}_{-} \mathrm{C} S \mathrm{~S}$ & $\perp \Lambda \quad$ CARE.HOME \\
\hline & M TH_D.N & $\Lambda$.TH_C.M & $\perp \quad$ CARE.HOME \\
\hline & $M$ TH_D.N & $\Lambda$ TH_C.L & $\Lambda_{\|}$CARE_AMBULAT \\
\hline & M IH_D.S & $\Lambda$ TH_C.N & $\Lambda$. CARE.AMBULAT \\
\hline & $M$ ITH_D.S & $\Lambda \mathbf{\| T H}_{-} \mathrm{C} . S$ & $\Lambda$ CARE.AMBULAT \\
\hline & $M$ ITH_D.S & $\Lambda$. ${ }^{T H} \_$C.M & $\Lambda$ CARE.AMBULAT \\
\hline & IN IH_D.S & L 1 TH_C.L & $\Lambda$. CARE.HOSPITAL \\
\hline & $\Lambda$.TH_D.M & $\Lambda$ TH_C.N & $\Lambda$. CARE.HOSPITAL \\
\hline & $\perp \_$॥TH_D.M & $\Lambda_{\mathbf{I}} \mathrm{TH}_{-} \mathrm{C} . \mathrm{S}$ & $\Lambda$ CARE.HOSPITAL \\
\hline & $\Lambda$.TH_D.M & $\Lambda$.TH_C.M & $\Lambda$ ICARE.HOSPITAL \\
\hline & $\Lambda$-TH_D.M & $\Lambda \quad \mathrm{TH}_{-} \mathrm{C} . L_{\mathrm{L}}$ & $\Lambda$. CARE.HOSPITAL \\
\hline & $\perp \Lambda$ TH_D.L & $\Lambda \quad \mathrm{TH}_{-} \mathrm{C} . \mathrm{N}$ & $\Lambda \quad$ CARE.CARE \\
\hline & $\Lambda$ TH_D.L & $\Lambda$ - ${ }^{\mathrm{T}} \mathrm{H}_{-} \mathrm{C} . \mathrm{S}$ & I CARE.CARE \\
\hline & $\perp \Lambda$ TH_D.L & $\Lambda$.TH_C.M & IN CARE.CARE \\
\hline & $\Lambda$ TH_D.L & $\Lambda$ TH_C.L & I CARE.CARE \\
\hline
\end{tabular}

b)

Fig. 9. a) the list of fuzzy rules $\operatorname{LoR}_{\mathrm{DIET}}$ for the diet; b) the list of fuzzy rules $\operatorname{LoR}_{\mathrm{CARE}}$ for the type of care.

Recommendations for DIET and CARE answer the question WHICH?, and are selected from the corresponding lists of possible finite sets.

Since it is clear from the reasoning in the beginning of this section that FEM DIET and FEM CARE must answer the question WHICH?, it is necessary to fuzzify (or verbalize) their digital output values $\left[\mathrm{L}_{\mathrm{DIET}}\right]$ and $\left[\mathrm{L}_{\mathrm{CARE}}\right]$ in order to be able to choose the proper answers from the corresponding finite sets of verbalized solutions with some certainty: from the set of numbered diets in case a), and the list of possible types of treatment in case b).
An example of secondary fuzzification for concrete value of $\left[\mathrm{L}_{\text {DIET }}\right]=0.54$, received when LEVERAGE inputs from the FSM network were: $\mathrm{TH}_{\Sigma \mathrm{C}}^{\star}=0.25$ and $\mathrm{TH}_{\Sigma \mathrm{A}}^{\star}=0.25$ is presented in Fig. 11. The recommended diet for the patient is number III with the certainty $\mu=0.95$ or diet number II with the certainty $\mu=$ 0.05 only. Obviously the patent will receive diet number III.

A similar process of the selection for the same patient of proper type nursing and treatment is demonstrated in the Fig. 12. After the secondary fuzzification of the digital output value $\left[\mathrm{L}_{\mathrm{CARE}}\right]=$ 0.45 of the FEM CARE received when the $\mathrm{TH}_{\Sigma \mathrm{D}}^{\star}=0.25$ and $\mathrm{TH}_{\Sigma \mathrm{C}}^{\star}=0.25$ the most certain recommendation (the certainty $\mu=$ 
0.65) is HOSPITAL and/or AMBULAT (the outpatient

treatment), but with the less certainty: $\mu=0.35$.

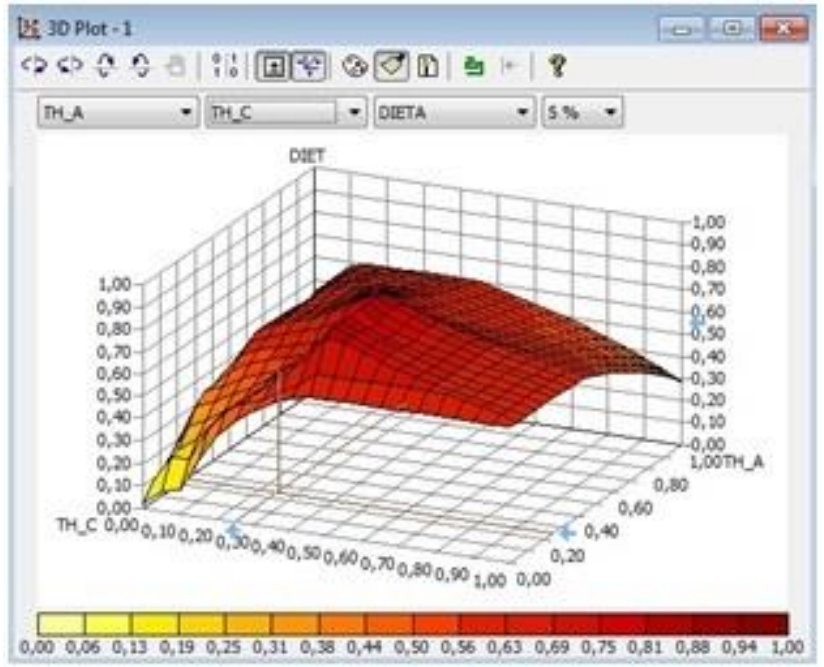

a)

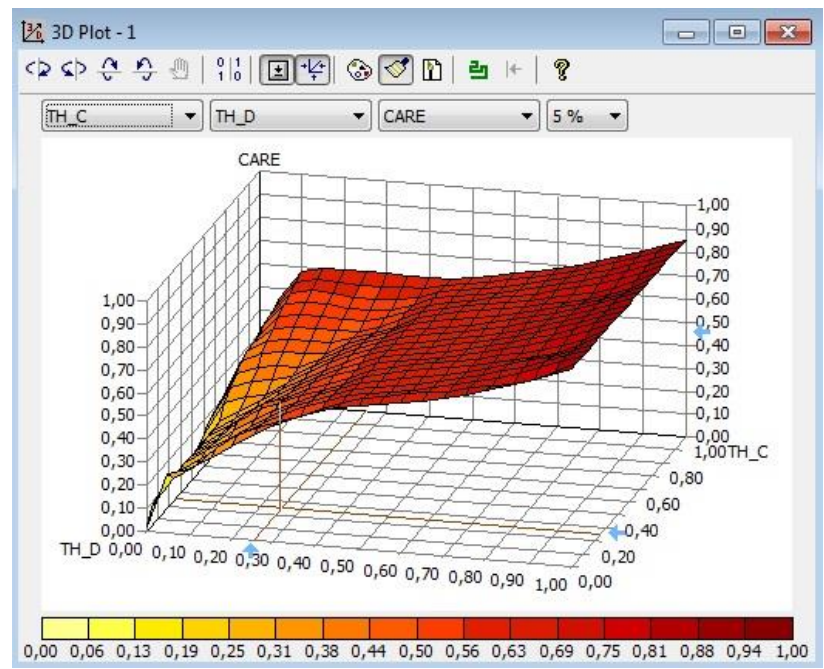

b)

Fig. 10. a) $\left[\mathrm{L}_{\mathrm{DIET}}\right]$ as a function of $\mathrm{TH}_{\Sigma \mathrm{C}}^{\star}\left(\mathrm{TH} \_\mathrm{C}\right)$ and $\mathrm{TH}_{\Sigma \mathrm{A}}^{\star}\left(\mathrm{TH} \_\mathrm{A}\right)$; b) $\left[\mathrm{L}_{\mathrm{CARE}}\right]$ as a function of $\mathrm{TH}_{\Sigma \mathrm{D}}^{\star}\left(\mathrm{TH} \_\mathrm{D}\right)$ and $\mathrm{TH}_{\Sigma \mathrm{C}}^{\star}\left(\mathrm{TH}_{-} \mathrm{C}\right)$

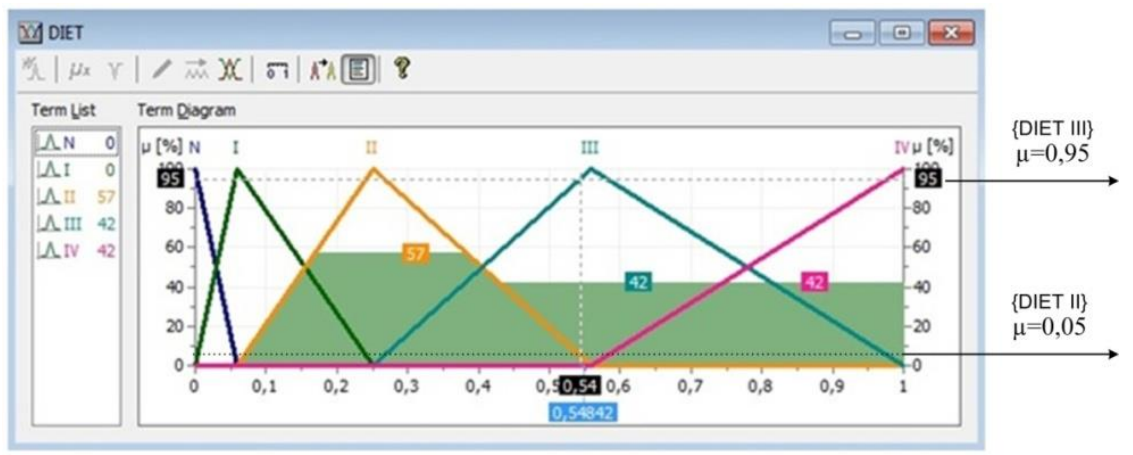

Fig. 11. An example of fuzzification of the output of FEM DIET for diet selection

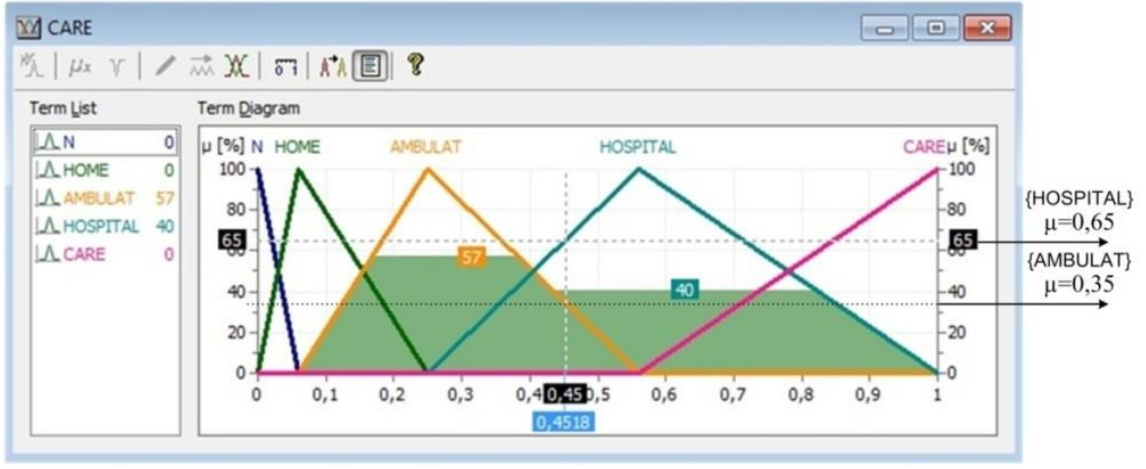

Fig. 12. An example of fuzzification of the output of FEM CARE for selection of the best type of nursing and treatment

\section{Conclusion and future works}

This paper suggests extend the earlier proposed XAI-based medical diagnostic decision support system with a new functionality (here called as LEVERAGE) for the treatment and care elderly patients. First of all the extension was analyzed as a partial case of the universalized fuzzy SWOT maps network, and the idea was successfully simulated and confirmed its vitality. So, we have obtained very promising breakthrough in believes that the theories about diseases are good ones only if they offer treatment as well.
The most important planned research works in this field are the following: 1) to develop a pilot LEVERAGE software model; 2) to gather a mixed team of medical and informatics researchers for the analysis of the chosen complex of elderly syndromes and preparation of corresponding list of fuzzy rules; 3) to create a LEVERAGE prototype for those syndromes; 4) perform a correlation comparison between real clinical results and LEVERAGE recommendations. 


\section{Acknowlendgements}

The coauthors team is eager to express their acknowledgements to the doctors and professors Vita Lesauskaite, Gyte Damuleviciene and Jurgita Knasiene from Clinical Department of Geriatrics of Lithuanian University of Health Science, for the formulation of the main goal of this research and for patient consultation and discussions during the whole process.

\section{REFERENCES}

[1] M. M Helms, J. Nixon, (2010),"Exploring SWOT analysis - where are we now?", Journal of Strategy and Management, Vol. 3 Iss 3 pp. 215 251 Permanent link to this document: http://dx.doi.org/10.1108/17554251011064837

[2] V. Lesauskaitè, G. Damulevičienè, J. Knašienè, E. Kazanavičius, A. Liutkevičius, A. Janavičiūté, Older adults - potential users of technologies // Medicina. Basel : MDPI AG. ISSN 1010-660X. eISSN 1648-9144. 2019, vol. 55, no. 6, art. no. 253, p. [1-9]. DOI: 10.3390/medicina55060253.

[3] V. Petrauskas, R. Jasinevicius, E. Kazanavicius, Z. Meskauskas, Concept of a System Using a Dynamic SWOT Analysis Network for Fuzzy Control of Risk in Complex Environments, Mathematics and Computer Science (MCS). Mathematics and Computer Science. Vol. 5, No. 2, 2020, pp. 42-55. doi: 10.11648/j.mcs.20200502.11 (ISSN Print: 2575-6036; ISSN Online: 2575-6028), 2020

[4] Z. Meskauskas, R. Jasinevicius, E. Kazanavicius, V. Petrauskas, XAIBased Fuzzy SWOT Maps for Analysis of Complex Systems 2020 IEEE International Conference on Fuzzy Systems (FUZZ-IEEE): Proceedings of 2020 IEEE International Conference on Fuzzy Systems (FUZZ-IEEE)IEEE Catalog Number: CFP20FUZ-ART ISBN: 978-17281-6932-3;8p.p

[5] V. Petrauskas, R. Jasinevicius, E. Kazanavicius, Z. Meskauskas, CWW elements to enrich SWOT analysis, Journal of Intelligent and Fuzzy Systems, vol. 34, no. 1, pp. 307-320, 2018.

[6] V. Petrauskas, G. Damulevičienè, A. Dobrovolskis, J. Dovydaitis, A. Janavičiūtè, R. Jasinevičius, Kazanavičius, J. Knašienė, V. Lesauskaitè, A. Liutkevičius, Ž. Meškauskas, XAI-based medical decision support system model // International journal of scientific and research publications. New Delhi :IJSRP Inc. ISSN 2250-3153. 2020, vol. 10, no. 12, p. 598-607. DOI: 10.29322/IJSRP.10.12.2020. p 10869.

[7] R. Jasinevicius, V. Petrauskas, Fuzzy expert maps: The new approach, in: Proceedings of 2008 IEEE International Conference on Fuzzy
Systems (IEEE World Congresson Computational Intelligence), HongKong, China, pp. 1511-1517,2008.

[8] R. Jasinevičius, R. Krušinskiené, V. Petrauskas, A. Tkaciov. Dynamic fuzzy expert maps: idea and implementation // Information Technologies' 2011: proceedings of the 17th international conference on Information and Software Technologies, IT 2011, Kaunas, Lithuania, April 27-29, 2011 / Edited by R. Butleris, R. Butkiene ; Kaunas University of Technology. Kaunas: Technologija. ISSN 20290020. 2011, p. 17-22. [Conference Proceedings Citation Index]

[9] V. Petrauskas, R. Jasinevicius, G. Damuleviciene, A. Liutkevicius, A. Janaviciute, V. Lesauskaite, J. Knasiene, Z. Meskauskas, J. Dovydaitis, V. Kazanavicius, R. Bitinaite-Paskeviciene, Explainable Artificial Intelligence-Based Decision Support System for Assessing the Nutrition Related Geriatric Syndromes //(17 p.p., 2021, in press)

[10] [https://en.wikipedia.org/wiki/Ralph_Waldo_Emerson.

[11] https://en.wikipedia.org/wiki/Fuzzy_logic

\section{AUTHORS}

First Author - Vytautas Petrauskas, Associate Professor, Project Researcher, Centre of Real Time Computer Systems at Kaunas University of Technology, Email address:

vytautas.petrauskas@ktu.lt.

Second Author - - Raimundas Jasinevicius, Professor, Project Researcher, Centre of Real Time Computer Systems at Kaunas University of Technology, Email address:

raimundas.jasinevicius@ktu.lt.

Third Author - Egidijus Kazanavicius, Professor, Head of Centre, Centre of Real Time Computer Systems at Kaunas University of Technology, Email address: egidijus.kazanavicius@ktu.lt.

Fourth Author - Zygimantas Meskauskas, Engineer, Project Junior Researcher, Centre of Real Time Computer Systems at Kaunas University of Technology, Email address:

zygimantas.meskauskas@ktu.lt..

Correspondence Author - Vytautas Petrauskas, email address vytautas.petrauskas@ktu.lt, alternate email address vytaupetra@gmail.com. 